\title{
IDENTIFICAÇÃO DE PERDAS EM PROCESSO DE E-COMMERCE SEGUNDO O REFERENCIAL DO SISTEMA TOYOTA DE PRODUÇÃO
}

\author{
M. C. SOUZA, G. G. SAUERESSIG, J. G. UBIRAJARA JUNIOR, J. LUCHESE, J. M. BAUER, e M. A. SELLITTO* \\ Universidade do Vale do Rio dos Sinos (UNISINOS) \\ sellitto@unisinos.br
}

Artigo submetido em 07/07/2015 e aceito em 08/12/2016

DOI: 10.15628/holos.2016.3191

\section{RESUMO}

O cenário brasileiro de vendas eletrônicas vem crescendo significativamente e, com isso, o gerenciamento da informação e do processo se tornam elemento essencial nas organizações que buscam uma maior fatia neste segmento. O presente artigo tem como objetivo a identificação de perdas no processo de e-commerce do Walmart Brasil, à luz dos princípios básicos do Sistema Toyota de Produção. Após revisão teórica é apresentado o processo de recebimento de pedidos, sistema de gestão online e logística, etapas do processo de venda online da empresa, com a observação das características mais profundas a respeito dos processos realizados. O método utilizado foi um estudo de caso embasado em entrevista e análise de dados. Os principais resultados apresentaram um número elevado de perdas no processo de e-commerce.

PALAVRAS-CHAVE: Sistema Toyota de Produção. Varejo. e-Commerce. Sete Perdas.

\section{IDENTIFICATION OF LOSS IN PROCESS OF E-COMMERCE BY REFERENCE OF THE TOYOTA PRODUCTION SYSTEM}

\begin{abstract}
The Brazilian situation electronic sales has been growing significantly. And with that, the information management and process become essential element in organizations seeking a larger share in this segment. This article aims to identify losses in the process of ecommerce for Walmart Brazil, in the light of the basic principles of the Toyota Production System. After the
\end{abstract}

theoretical review, the process of receiving applications, online management and logistics system, process steps online sale of the company, with the observation of the deeper features about the processes performed is presented. The method used was a case study and grounded in interview and data analysis. The main results showed a high number of losses in the process.

KEYWORDS: Toyota Production System. Retail. e-Commerce. Seven loses. 


\section{INTRODUÇÃO}

O mercado de vendas eletrônicas no Brasil vem crescendo em média $25 \%$ a cada ano através da mudança de comportamento de compra dos brasileiros que buscam alternativas para otimizar seu tempo. O crescimento desta modalidade é diretamente ligado ao acesso dos brasileiros à internet.

Segundo o jornal Data Folha (2013) a previsão de vendas online já era otimista, e de acordo com o e-bit o crescimento chegou a $28 \%$ e o faturamento do comércio eletrônico no Brasil foi de $\mathrm{R} \$ 28,8$ bilhões ao longo do ano de 2013. No ano de 2014 o setor movimentou $\mathrm{R} \$ 35,8$ bilhões, crescendo, nominalmente, $24 \%$ em relação ao ano de 2013 . Para Reddy \& Divakar (2014), o e-commerce está se tornando rapidamente o meio mais aceito de fazer negócio.

O número de consumidores na internet subiu, superando o número total de consumidores no ano de 2012. Isso mostra que a constância de compra anual pela internet do brasileiro é elevada, aumentando assim, ano a ano. De acordo com o NPS (Net Promoter Score) (2013) usada para computar dados que indicam a satisfação e fidelização dos clientes de comércio eletrônico, indicaram que o comércio eletrônico brasileiro em 2013 foi satisfatório. Um comparativo é o mês de dezembro, onde há um grande número de pedidos e entregas, segundo o NPS dezembro de 2013 foi de 46,93\% enquanto o mesmo período de 2012 foi 40,96\%. Esse é um reflexo do maior preparo dos empresários em relação a períodos de grande consumo como é o caso do Natal (eBit, 2014).

O mercado de vendas pela internet no Brasil é dividido em cerca de cinco grandes sites de propriedade dos três maiores varejistas do país, estes concorrem com milhares de pequenos comerciantes, sejam pessoas físicas ou jurídicas, que a todo momento publicam promoções e modelos diferenciados na mídia e para manter-se competitivo neste mercado, de modo geral, as empresas focam em analisar o comportamento de compra dos consumidores, ações de publicidade, promoções em tempo real, entre outros (Mesquita, 2014).

A Internet tornou-se um componente essencial do quotidiano social e financeira. A Internet não é importante para usuários individuais, mas também para as organizações, porque as organizações que oferecem comércio online podem alcançar uma vantagem competitiva, servindo clientes em todo o mundo (Mohammada, Thabtahb \& Mccluskey, 2015). Hoje quase todos os produtos vendidos no mercado podem ser encontrados online, e varejistas online se envolvem em constantemente em atividades promocionais (Jiang et al., 2015).

As classes econômicas C e D estarão cada vez mais presentes no consumo em comércio eletrônico, isso devido a popularização de celulares e smatphones com acesso à internet e navegadores completos, redução do custo de uso do serviço de dados para internet e o crescimento da banda larga em dispositivos móveis. Umas das principais estratégias das empresas que atuam nesta modalidade de vendas são: entrega rápido, melhor preço, garantia de qualidade, rapidez na transação e facilidades de pagamento. Todas estas ações requerem altos 
investimentos e podem ser transformadas em prejuizo se não forem bem administradas (Mesquita, 2014).

O objetivo deste artigo é apresentar os conceitos utilizados nas perdas do STP e associálos na aplicação em uma rede varejista de comércio eletrônico. Observação documental e entrevistas foram as fontes das informações de perdas ocorridas nos processos da empresa estudada, utilizando-se o método qualitativo de pesquisa. Foram observados os processos de estocagem, recebimento de pedidos, expedição, entrega, e pós-venda com o intuito de identificar e qualificar as perdas, de acordo com a ótica do Sistema Toyota de Produção.

Na literatura do período de 2012 a 2015, artigos relacionando as Perdas propostas por Shingo e o setor de e-commerce não foram encontrados. Para tanto, alguns artigos mencionando o setor em estudo já foram explanados. Reddy e Divekar (2014), estudaram os desafios enfrentados pelas empresas de comércio eletrônico na Índia e métodos empregados para superá-los. Jiang et al. (2015) demonstraram que a promoção de preços online e recomendações de produtos devem ser considerados em conjunto. Através de descontos atrativos nos preços os varejistas podem motivar os clientes a comprar o produto promovido. Mohammada, Thabtah e McCluskey (2015) trataram do Phishing que é considerada uma forma de ameaças via web e definida como a arte de representar um website de uma empresa honesta com o objetivo de obter credenciais confidenciais do usuário, como nomes de usuário, senhas e sociais números de segurança. Por fim, Marett et al. (2015) utilizaram o e-commerce e teorias de adoção para construir um modelo de confiança e de risco como preditores de celular usar os benefícios em uma amostra de usuários móveis atuais no sul do Afeganistão. As respostas coletadas de uma pesquisa com mais de sete mil cidadãos afegãos foram usadas para testar a modelo de pesquisa.

Além desta introdução, na seção 2 são apresentados o contexto histórico do Sistema Toyota de Produção, assim como os princípios básicos de construção e as sete perdas. Na seção 3 o método de pesquisa e a estrutura do estudo. Na seção 4 o estudo de caso com a análise dos resultados obtidos. $O$ artigo é finalizado com as considerações finais, na seção 5 .

\section{REFERENCIAL BOBLIOGRÁFICO}

\subsection{Contextualização: Sistema Toyota de Produção}

Foi em um contexto de crise mundial que a Toyota chamou atenção aos olhos do mundo, e seu sistema de produção, que mais tarde ficaria conhecido como Sistema Toyota de Produção STP, e que revolucionaria os conceitos e práticas produtivas, começou a ser estudado por empresários e pesquisadores acadêmicos. A crise do petróleo em 1973 foi seguida de uma grande recessão mundial. Em 1974 o Japão enfrentava graves problemas econômicos: havia caído para nível zero de crescimento. Mesmo assim, a Toyota Motor Company apresentava 
ganhos acima do esperado (Ohno, 1997). Este sucesso se deu graças aos princípios, métodos e técnicas que constituem o STP, e da aplicação concatenada de cada um deles (Ghinato, 1994).

O Sistema Toyota de Produção (STP) é considerado o grande responsável pelo crescimento da indústria japonesa. Alguns autores consideram-no com potencial suficiente para lançar a economia mundial em uma nova fase de expansão (Ghinato, 1994; Spear \& Bowen, 1999).

Focado na eliminação total de desperdícios, definidos por Womack e Jones (1998), como toda atividade humana que consome recursos sem criar valor, o STP é sustentado por dois pilares: o Just in Time (JIT) e a Autonomação (Jidoka, em japonês), ou automação com um toque humano (Ghinato, 1994; Falcão, 2001; Neto, 2006).

Não se deve confundir JIT com STP. O Just in Time é apenas um meio de alcançar o objetivo principal do Sistema Toyota de Produção. O Just in Time é visto como um conceito revolucionário que causou uma completa mudança de paradigmas no campo de conhecimento em produção. JIT, operacionalmente, significa que cada processo deverá ser suprido com os materiais necessários, na quantidade necessária, no local correto e na hora correta.

"o Just-in-Time é, única e exclusivamente, uma técnica que se utiliza de várias normas e regras para modificar o ambiente produtivo, isto é, uma técnica de gerenciamento, podendo ser aplicada tanto na área de produção como em outras áreas da empresa. (Ghinato, 1994, p.171)"

A autonomação é a automação com um toque humano, ou seja, com autonomia. Consiste em conceder ao operador ou à máquina o poder de parar o processo sempre que detectar falhas na produção. O objetivo é impedir que os defeitos continuem por várias peças até serem detectados. Ao parar a linha de produção, o problema fica visível para o operador e para toda sua equipe e gerência, o que facilita ações que eliminem os erros (Ghinato, 1994). Em fevereiro de 2010, Akio Toyoda, Presidente da Toyota Motors, discutindo a filosofia da empresa, disse se tratar de uma tradição e de motivo de orgulho na Toyota, a maneira como encaram seus problemas, sem fingir não tê-los percebido: "Às vezes, nós encontramos defeitos. Mas, em tais situações, sempre paramos, nos esforçamos para entender o problema, e fazer mudanças para melhorar ainda mais" (Monden, 2011, p.XXV).

\subsection{Princípios básicos de construção do Sistema Toyota de Produção (STP)}

O STP é estruturado, além de seus pilares de sustentação, just-in-time e autonomação, de uma base necessária para compreensão e utilização importante para o seu eficaz funcionamento (Falcão, 2001). Os princípios básicos segundo Antunes (1998) são: i) Mecanismos da Função Produção (MFP); ii) princípio do não-custo e iii) análise das perdas nos sistemas produtivos. Os três princípios básicos serão descritos a seguir: 
Segundo Shingo (1996a), o MFP é um sistema de produção similar a uma rede funcional de processos e operações. Os processos são definidos como sendo a transformação de matériasprimas em produtos acabados, em contra partida, as operações são todas as ações que executam tal transformação. A análise do processo examina o fluxo de material ou produto, durante a transformação da matéria-prima no sistema de produção e a análise das operações examina o trabalho realizado sobre os produtos pelo trabalhador e pelas máquinas. Para Antunes et al.(2008) a função processo é o fluxo de materiais ou produtos em diferentes estágios de produção. Por sua vez, a função operação é definida como a análise dos diferentes estágios, nos quais os trabalhadores e os recursos encontram-se relacionado.

O segundo princípio do STP é caracterizado como o princípio do não custo e, segundo Shingo (1996a), os produtores devem deixar que o mercado determine o preço dos produtos, conforme apresenta a Equação 1.

$$
\text { Preço }- \text { Custo }=\text { Lucro }
$$

Para tanto, a única maneira de aumentar os lucros é através da redução dos custos. Que por sua vez, só será possível através da eliminação total das perdas (Shingo, 1996a). Ghinato (1996) salienta que a lógica anterior, onde o "Preço = Custo + Lucro" era ineficaz, as empresas deslocavam para os clientes finais os custos adicionais muitas vezes decorrentes de uma ineficiência nos seus processos.

Sendo o STP um sistema de gerenciamento da produção que tem como objetivo aumentar o lucro através da redução dos custos, faz-se necessário consistentemente identificar e eliminar atividades que não agregam valor ao produto, ou seja, que representam perdas no processo produtivo (Ghinato, 1996).

\subsection{As perdas do Sistema Toyota de Produção}

De acordo com o STP, a capacidade de produção em um sistema produtivo é o resultado da soma de trabalho e perdas: Capacidade de Produção = trabalho + perdas $($ Ohno, 1997). O trabalho compreende as atividades que levam o processo a efetivamente alcançar seu fim. São de dois tipos: i) Trabalho que adiciona valor refere-se ao trabalho efetivo, que representa algum tipo de processamento, ou seja, aquilo que agrega valor ao produto e, ii) Trabalho que não adiciona valor, representado por atividades que dão suporte ao processamento propriamente dito. As perdas são todas as atividades desnecessárias que geram custos e não agregam valor ao produto e que, portanto, devem ser eliminadas do sistema de produção.

O STP prega a constante busca pela eliminação das perdas e minimização dos trabalhos que não agregam valor (Bornia, 1995, Falcão, 2001, Ghinato, 1994, Ohno, 1997, Shingo, 1996a). 
No STP, o aumento da eficiência só pode ser alcançado quando se produz zero perda e eleva-se a porcentagem de trabalho que adiciona valor para 100\%. A primeira etapa necessária para diagnosticar as perdas existentes no processo, é através da identificação (Ohno, 1997). No STP são consideradas sete classes de perdas (Antunes, 1995, Antunes, 1998, Ohno, 1997, Shingo, 1996a,Shingo 1996b).
a) Perdas por superprodução;
b) Perdas por transporte;
c) Perdas no processamento;
d) Perdas por produzir produtos defeituosos;
e) Perdas por estoque;
f) Perdas por movimentação;
g) Perdas de tempo disponível (espera).

Perdas por superprodução (quantitativa e por antecipação): representam aquelas perdas decorrentes da produção antecipada de produtos, produção esta que ocorre antes do momento necessário, como consequência, produtos permanecem estocados aguardando o momento de serem comercializados ou devido à produção excessiva, decorrente da produção além da quantidade programada ou necessária, ou por compra de matérias-primas em quantidade maior do que é necessário (Antunes \& Klippel, 2002, Anzanello et al., 2009).

Segundo Ohno (1997) as perdas por superprodução são críticas por esconderem outras perdas, como por exemplo, as perdas por produtos defeituosos, perdas decorrentes da espera do processo e do lote. Os adiantamentos de produção na suposição de uso futuro são desperdícios. Faça somente o necessário, aquilo que o cliente deseja. Esse tópico ganha particular interesse para a indústria ocidental (Slack, Chambers \& Johston, 2002, Shingo, 1996b, Moreira, 2011, Corrêa \& Gianesi, 1993).

Antunes (1995) demonstra ações para atacar as perdas por superprodução:

a) Melhoria no processo de estocagem, através do nivelamento das quantidades e sincronização dos processos, visando minimização ou eliminação da necessidade de estoques intermediários.

b) Melhoria no processo de estocagem, por meio da operação em fluxo de uma só peça, ou produção em pequenos lotes. Torna-se também necessário a melhoria no layout da fábrica.

c) Melhoria na operação, através da melhoria dos tempos de preparação de máquinas e ajustes. Os tempos de preparações longos acarretam a necessidade de produção de grandes lotes, resultando na existência de estoques intermediários desnecessários e longos tempos de lead times. 
Desse modo, a filosofia enxuta sugere que se produza somente o que é necessário no momento e, para isso, que se reduzam os tempos de set up, se sincronize a produção com a demanda, se compacte o layout da fábrica e assim por diante (Menegon et al., 2003).

Perdas por transporte: a atividade de transporte é uma operação que não agrega valor ao produto uma vez que a forma do material não se altera desde o início até o fim do ciclo. Para tanto, busca-se a eliminação desta operação pela mudança do layout das instalações. Mecanizar idealmente um transporte, por exemplo, pode eventualmente melhorar a eficiência desta operação, mas no máximo ocasionará uma redução dos custos de transporte não representando em ganhos para o sistema como um todo (Antunes \& Klippel, 2002).

A atividade de transporte e movimentação de materiais de um lado para o outro é vista como perda por não agregar valor ao produto, mas é necessária devida a restrições de processo e instalações, que impõem grandes distâncias a serem percorridas entre o material durante o processo. Para Menegon et al. (2003), os custos de transporte podem ser reduzidos se o material for entregue no local de uso.

Para Antunes (1995), é necessário adotar dois tipos de ações sequenciadas para atacar as causas fundamentais das perdas por transporte. i) executar ações a fim de promover melhorias do layout, buscando desta forma a eliminação do transporte; e ii) executar melhorias no sentido da mecanização e automatização dos trabalhos, sendo difíceis de serem eliminados no curto e médio prazo.

A eliminação ou redução do transporte deve ser encarada como uma das prioridades no esforço de redução de custos, pois, em geral, o transporte ocupa $45 \%$ do tempo total de fabricação de um item (Ghinato, 1996).

Perdas no processamento em si: neste tipo de perda, inúmeras atividades podem ser realizadas sem que contribuam para a melhoria da qualidade do produto, sendo, desta forma, desnecessárias. Neste caso, é preciso um trabalho de investigação pela agregação de valor para a identificação das mesmas e eliminação deste tipo de perdas (ANTUNES; KLIPPEL, 2002), portanto, são parcelas do processamento não necessárias para que o produto adquira suas características funcionais (Anzanello et al., 2009).

Segundo Corrêa e Gianesi (1993), pode haver perdas no próprio processo produtivo que podem ser eliminadas através de questionamentos como e porque determinado componente deve ser feito, qual sua função no produto, porque esta etapa no processo é necessária. Para ele, é comum que os gerentes se preocupem em fazer o processo rápido sem questionar o porquê de se estar fazendo.

Antunes (1995) reforça a ideia de que para identificação desta perda, é necessário sempre fazer duas perguntas básicas e que podem ser respondidas através das lógicas das técnicas de análise: Por que este tipo de produto deve ser produzido? E por que este método deve ser utilizado neste tipo de processamento? 
Perdas devido à fabricação de produtos defeituosos: a fabricação de produtos defeituosos, que não atendam às especificações de qualidade projetadas, constitui um desperdício que aumenta os custos de produção. Para a sua eliminação deve-se realizar uma inspeção visando identificar e prevenir a ocorrência destes produtos. A simples identificação destes produtos não irá resolver o problema, uma vez que ele tenderá a se repetir. Deve-se atacar a causa e não a consequência (Antunes \& Klippel, 2002).

Para Anzanello et al. (2009), trata-se do tipo de perda mais comum e visível, pois se materializa no objeto da produção, exigindo retrabalho ou refugo do produto, implicando assim, desperdício de disponibilidade de mão de obra, materiais, disponibilidade de equipamentos, movimentação de materiais defeituosos, armazenagem entre outros (Corrêa \& Gianesi, 1993).

Slack, Chanbers e Johston (2002) citam que este tipo de perda é normalmente bastante significativo nas empresas, mesmo que as medidas reais de qualidade sejam limitadas, os custos de qualidade são normalmente muito maiores do que se têm sido considerados, sendo, portanto mais importante atacar.

Perdas nos estoques: um dos paradigmas derrubados pelo STP é o de que havia necessidade de formação de estoques no processo produtivo (estoque em processo) ou no almoxarifado/expedição (matéria-prima/produto acabado). O desenvolvimento do Just-in-Time comprovou que a existência de estoques na realidade apenas encobre imperfeições, constituindo-se em desperdício. A eliminação de estoques tanto no almoxarifado como nos produtos em fabricação deve ser perseguida (Antunes \& Klippel, 2002). Para tanto, as perdas nos estoques referem-se aos custos associados à manutenção e movimentação de estoques de matérias-primas, material em processamento e produtos acabados (Anzanello et al., 2009).

Segundo Shingo (1996a) o acúmulo de estoque pode ocorrer devido à ineficiência no processo quanto nas operações. Os acúmulos provenientes de processos resultam em três tipos de estoques: estoque criado pela produção antecipada (quando os ciclos de produção são mais longos que os ciclos de entrega); estoque produzido por antecipação como preocupação em relação às flutuações da demanda e estoques produzidos para compensar o deficiente gerenciamento da produção e as esperas provocadas pela inspeção e transporte.

Ainda segundo Shingo (1996b), devem-se adotar três estratégias para atingir a produção ideal com estoque zero:

- Reduzir drasticamente os ciclos de produção;

- Eliminar as quebras e os defeitos, detectando duas causas e buscando solucionar a raiz do problema;

- Reduzir os tempos de setup para 10 minutos ou menos, possibilitando assim na produção em pequenos lotes e permitindo respostas mais rápidas às flutuações da demanda. 
Perdas no movimento: as perdas por movimento são aquelas relacionadas com os movimentos feitos pelos trabalhadores sem que estes sejam necessários. A redução dessas perdas tende a impactar positivamente sobre o tempo total de operação (Anzanello et al., 2009). Corrêa e Gianesi (1993) mencionam que o movimento desnecessário está presente nas mais diversas operações que se executam em uma fábrica, afirma ainda, que a economia nos movimentos aumenta a produtividade e reduz os tempos associados ao processo produtivo.

Segundo Slack, Chanbers e Johston (2002) um operador pode parecer ocupado, mas em algumas vezes, nada esta sendo agregado no produto pelo trabalho executado. Desta forma, movimentos desnecessários como abaixar para pegar uma ferramenta que poderia estar ao alcance das mãos em local padronizado. São responsáveis para que o tempo não aproveitado, e o movimento que, sendo efetuado, não agregam valor ao produto sejam considerados desperdícios (Shingo, 1996a).

Ainda segundo Shingo (1996b) o aperfeiçoamento dos equipamentos antes das melhorias nos movimentos básicos das operações, traz como resultado a mera mecanização de operações geradoras de desperdícios. Este tipo de perda pode ser eliminado através de melhorias baseadas no estudo de tempos e movimento. Tipicamente, a introdução de melhorias como resultado do estudo dos movimentos pode reduzir os tempos de operação em 10 a $20 \%$.

Perdas por espera: a falta de balanceamento no processo de produção ocasiona a paralisação de postos de trabalho resultando em baixa taxa de ocupação de equipamentos e paralisação da atividade humana, caracterizando as perdas por espera. Elas podem ocorrer, também, quando ocorre o setup dos equipamentos. O estudo da redução deste, através da Troca Rápida de Ferramentas - TRF, tem por finalidade a redução deste tipo de perda.

Para Corrêa e Gianesi (1993), referem-se ao material que está esperando para ser processado, formando filas e que visam garantir altas taxas de utilização de equipamentos. Havendo lotes maiores haverá formação de filas para o processamento do material nas operações subsequentes. Até esse estágio teríamos somente o desperdício em função da superprodução. Mas como os materiais são necessários em etapas do processo, ou setores posteriores, os processos também ficam aguardando o recebimento do material para poder iniciar a sua etapa.

Shingo (1996a) concorda neste entendimento considerando que existem dois tipos de perdas por espera: a do processo e a do lote. A espera do processo ocorre quando um lote de itens não processados fica esperando enquanto precedente é processado, inspecionado ou transportado. Já a espera no processo pode ser minimizada ou eliminada através do balanceamento das quantidades de produção e capacidades de processamentos entre processos e a sincronização da linha de produção na fábrica.

As sete perdas estão diretamente relacionadas com o conceito do Mecanismo da Função Produção. As perdas por superprodução, por transporte, no processamento em si, devido a fabricação de produtos defeituosos e nos estoques se relacionam com a função processo, na medida que visam racionalizar o fluxo do objeto de trabalho no tempo e no espaço. As perdas 
por espera e no movimento se relacionam diretamente com a função operação em função do fato de estarem focadas na análise do sujeito do trabalho - pessoas e equipamentos (ANTUNES, 1998).

Dessa maneira, tendo compreendido os fundamentos do Sistema Toyota de Produção e as fundamentações que envolvem o conceito das sete perdas, tem-se condições de avaliar o estágio atual da organização no que diz respeito a este fundamento e de identificar os desperdícios existentes do processo de e-commerce da empresa em estudo.

\section{METODOLOGIA}

Este trabalho teve como objetivo analisar e interpretar características a respeito dos processos de produção em um sistema de e-commerce, através de análise sobre investigações, hábitos, atitudes, tendências de comportamento, etc. Este método de pesquisa é compatível com a descrição do método qualitativo (Marconi \& Lakatos, 2010). É uma pesquisa descritiva, pois torna explícito os problemas identificados em uma empresa, neste caso, as perdas. A observação proporciona maior familiaridade com o problema de pesquisa, facilitando a compreensão do mesmo (Gil, 2010).

Os procedimentos utilizados foram a pesquisa bibliográfica, com uma revisão da teoria, utilizando-se trabalhos publicados anteriormente, como livros e artigos, com o intuito de conhecimento e fundamentação da pesquisa. Após a revisão teórica, foi feita uma pesquisa documental, para o reconhecimento e entendimento dos problemas da empresa. Para tanto, utilizou-se de entrevistas e de acesso a documentos fornecidos por gestores da organização. A observação, ou estudo de caso, foi a aplicação prática da teoria apresentada, o que nos fornece visão prática e possibilita a análise de acontecimento reais. O estudo de caso, apesar de significar levantamento e observação aprofundados de um determinado caso, pode ser limitado, por se referir unicamente ao caso estudado, restringindo-se (Marconi \& Lakatos, 2010, Gil, 2010).

O presente estudo considerou como população as empresas que utilizam-se de $e$ commerce como método de vendas e interação com o cliente. A amostra foi o sistema de $e$ commerce do Walmart, em nível de Brasil.

Neste trabalho foram utilizadas informações históricas de perdas ocorridas, informações atuais, como percentual de reclamações (insatisfação do cliente), atrasos de entrega, dados sobre realização de campanhas, utilização de tecnologias, etc. Os dados foram coletados através de informações documentadas pela empresa e fornecidas pelo vice-presidente da empresa, que permitiu a elaboração de uma lista minuciosa, com todas as atividades realizadas no processo de estocagem, recebimento de pedidos, expedição, entrega, e pós-venda. A observação dessas atividades permitiu a identificação de perdas no processo.

Buscou-se, ao final da pesquisa, qualificar as origens das perdas, de acordo com a ótica do Sistema Toyota de Produção. Como o método utilizado foi o qualitativo, a observação não contempla técnicas estatísticas, que são aplicadas em estudos quantitativos. 
A Figura 1 apresenta as cinco etapas contidas neste estudo para a identificação das perdas.

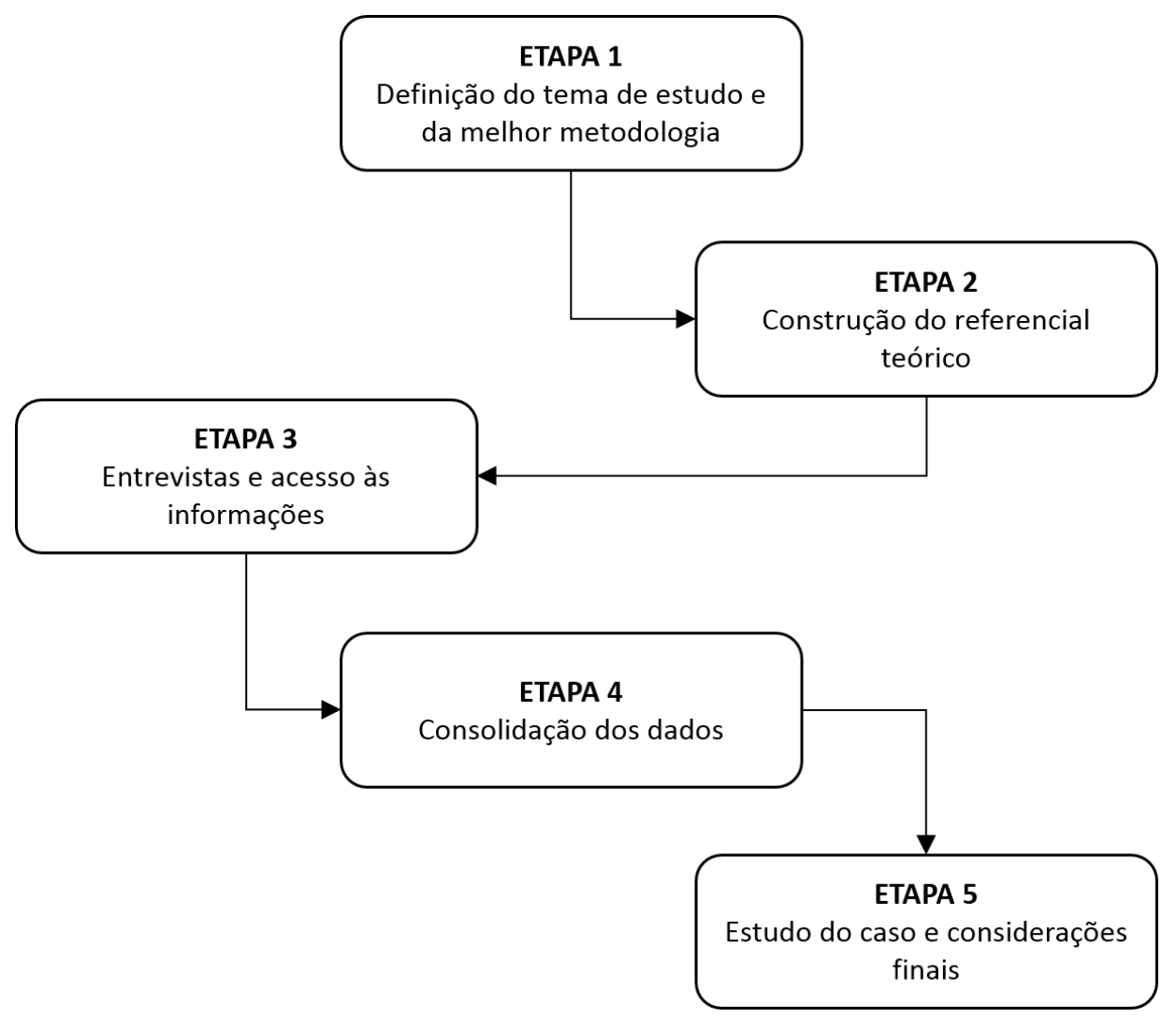

Figura 1: Etapas de elaboração da pesquisa. Fonte: Elaboração própria

Na etapa 1 foi definido tema da pesquisa, além de discutido o melhor método para a investigação desejada. O método de pesquisa qualitativo se mostrou o mais adequado para a averiguação de perdas em processos produtivos, e entrevistas aliadas à pesquisa documental foram as maneiras mais apropriadas de se obter acesso às informações necessárias. Elegido o assunto do estudo, iniciou-se uma fase de pesquisa de artigos, teses e dissertações indexados em bases nacionais (CAPES, bases de dados do portal BIREME) e internacionais como (EBSCo), afim de situar os objetivos da pesquisa à teoria já existente, o que se configura como sendo a etapa 2 do estudo. Após a construção do referencial teórico, passou-se para a etapa 3, ou fase de campo, com a coleta de dados em documentos que foram disponibilizados por gestores da organização, bem como a condução das entrevistas. A fase 4 é referente à leitura e compreensão dos dados e, por fim, a fase 5 compreende o estudo de caso, com a transformação das informações adquiridas em documentos e durante as entrevistas em conclusões, à luz da base teórica encontrada anteriormente. 


\section{APRESENTAÇÃO DO ESTUDO}

\subsection{Unidade de Estudo}

A unidade deste estudo é o segmento de vendas pela internet: o e-commerce do Walmart no Brasil. O Walmart está presente no país desde 1995 e em 2004 se tornou o 3 maior varejista do Brasil com as aquisições das redes Bompreço no NE e SONAE no Sul.

Atualmente é o maior varejista do mundo e único pela sua filosofia de negócio através de duas crenças: Custo Baixo Todo Dia (CBTD) e Preço Baixo Todo Dia (PBTD) na qual foi bemsucedida nos mais de 50 anos de sua existência.

Em 2011 pela forte tendência mundial de compras pela internet e impulsionado por outros países a empresa inaugurou o site de compras no Brasil. Inicialmente com produtos eletrônicos e eletrodomésticos superando todas as expectativas da empresa e, então começou a incluir novas categorias de produtos em seu site de vendas e parcerias com outros sites.

Atualmente, considerado um dos mais confiáveis e completos do Brasil, o site é tricampeão no prêmio Diamante Azul da e-bite, órgão que avalia a satisfação dos clientes que consumiram produtos do site, bem como sua segurança de compra e dados financeiros.

Apesar de tanto sucesso em vendas o negócio enfrenta sérios desafios, pois as margens dos produtos ofertados são muito baixas e algumas práticas para alavancar vendas utilizadas pela varejista como frete grátis e parcelamentos sem juros tem prejudicado seus resultados. Desta forma, a varejista necessita rever suas atividades e prevenir perdas para maximizar ao máximo seus ganhos.

\subsection{Resultados e Interpretação dos resultados}

O processo estudado é composto por uma série de etapas, nas quais são divididas em três departamentos: Departamento comercial; Sistema de Gestão online e Operações Logísticas.

A partir do entendimento das etapas, têm-se condições de avaliar as atividades mais detidamente a fim de identificar as perdas. O grande propósito de qualquer empresa, considerando o Sistema Toyota de Produção, deve ser o da prevenção de perdas. No sistema de e-commerce não é diferente. Neste sentido procurou-se, a partir das etapas e atividades desenvolvidas, analisar problemas específicos de perdas. A Figura 2 apresenta o fluxograma da empresa. 


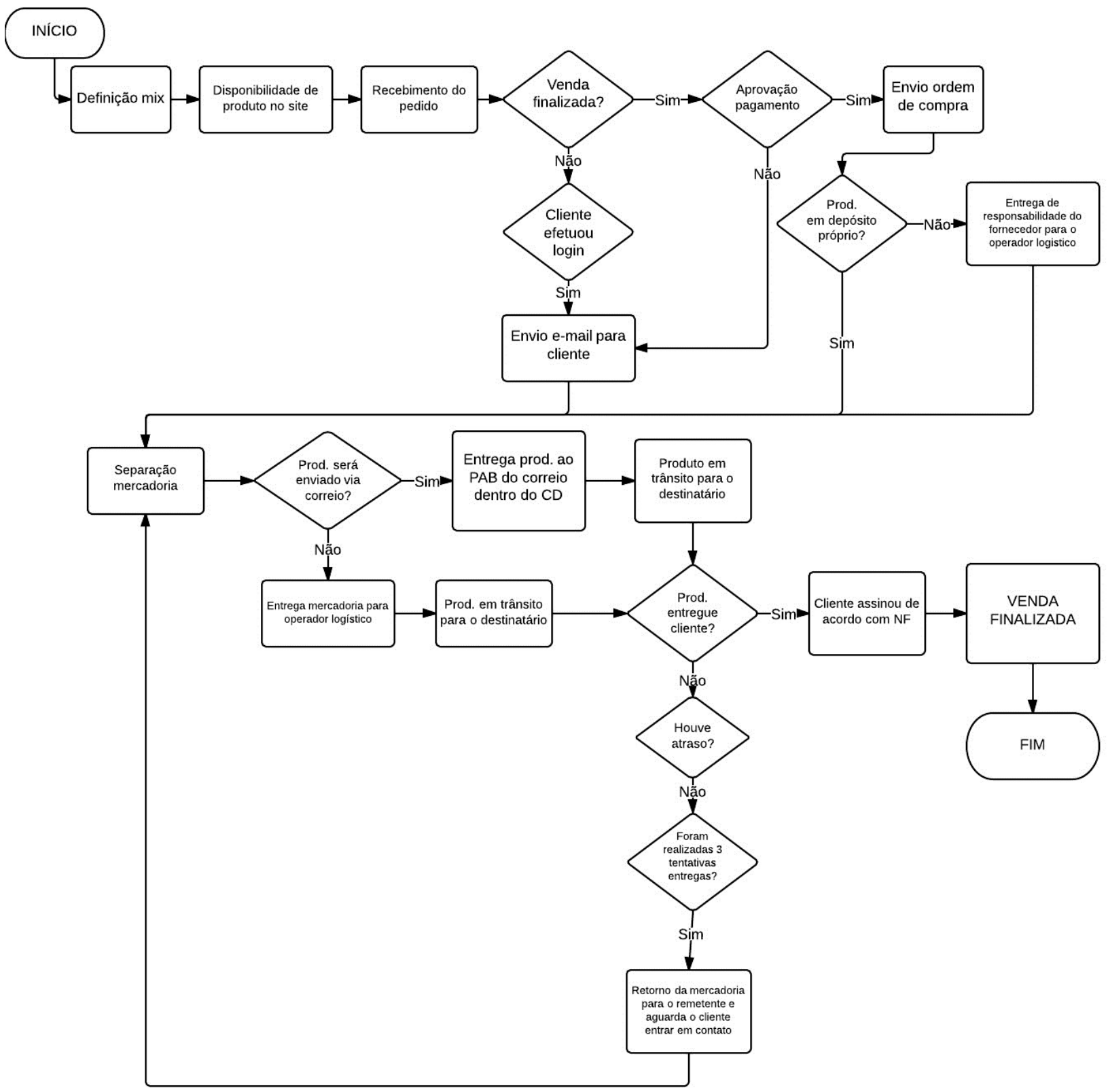

Figura 2: Fluxograma do e-commerce. Fonte: Elaboração própria

Quanto a definição das atividades de cada departamento, o quadro 1 apresenta as atividades pertencentes aos três departamentos. 


\begin{tabular}{|c|c|}
\hline Departamento & Atividades \\
\hline \multirow{2}{*}{ 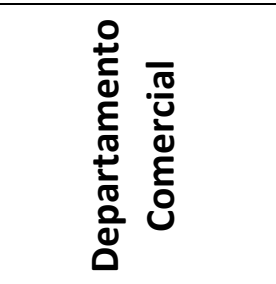 } & Definição mix \\
\hline & Disponibilidade dos produtos no site \\
\hline \multirow{4}{*}{ 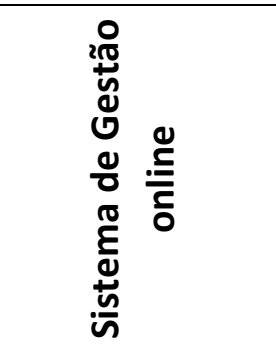 } & Recebimento do pedido do cliente \\
\hline & Envio de ordem de compra \\
\hline & $\begin{array}{l}\text { Entrega de responsabilidade do fornecedor para o operador } \\
\text { logístico }\end{array}$ \\
\hline & $\begin{array}{l}\text { Envio de e-mail para o cliente solicitando que finalize a compra } \\
\text { ou nova forma de pagamento }\end{array}$ \\
\hline \multirow{5}{*}{ 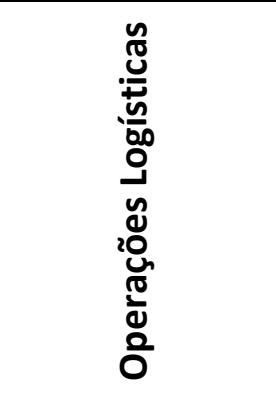 } & Separação da mercadoria para o despacho \\
\hline & $\begin{array}{l}\text { Entrega do produto ao PAB do correio dentro do Centro de } \\
\text { Distribuição }\end{array}$ \\
\hline & Produto em trânsito para o destinatário \\
\hline & Entrega da mercadoria para o operador logístico \\
\hline & $\begin{array}{l}\text { Retorno da mercadoria para o remetente e aguardar cliente } \\
\text { entrar em contato }\end{array}$ \\
\hline
\end{tabular}

Fonte: Elaboração própria

Na sequência, são apresentadas as perdas existentes no processo de e-commerce, após a entrevista realizada com o vice-presidente da empesa.

1) Perdas por superprodução: a empresa compete em vendas online com grandes e pequenas organizações especializadas em venda pela internet e telefone. $O$ aumento da concorrência traz a necessidade de diferenciação, para que a empresa mantenha-se competitiva no mercado. Na maioria dos produtos a empresa busca diferenciação pelo preço, através de compras em grande quantidade de um mesmo item, o que proporciona preços diferenciados nos contratos com fornecedores. A estocagem destes itens pode se tornar um problema quando as vendas não dão vasão suficiente para estes produtos. A situação é agravada quando se trata de eletroeletrônicos, como tablets, computadores e celulares, que se tornam obsoletos em um curto período de tempo devido aos lançamentos frequentes. Como ações para evitar grandes estoques parados, a empresa realiza análise de mercado, participa de feiras de tecnologia e procura acompanhar cronogramas de lançamento de tecnologia com os fornecedores. Como possui abrangência em todo o mundo, utiliza este acesso para facilitar as ações no Brasil.

Resultado da perda: há perda por superprodução. 
2) Perdas por transporte: gastos excessivos com logística e atraso na entrega dos produtos são problemas frequentemente enfrentados pelas empresas. Um produto anunciado no site com frete grátis vende 5 vezes mais do que se estivesse com frete pago. Para oferecer frete grátis ao consumidor e alavancar as vendas, a empresa precisa reduzir ao máximo o custo com transporte, e acaba sendo obrigada a trabalhar com subcontratações, onde cada produto passa por até 4 transportadoras diferentes até chegar ao consumidor final. Cerca de $13 \%$ das entregas chegam com atraso, e, 4\%, com avarias, necessitando substituição. Atualmente o custo de transporte da substituição por avaria é de responsabilidade da empresa, que não repassa o valor para as transportadoras.

Resultado da perda: há perda por transporte.

3) Perdas no processamento: a empresa vem enfrentando problemas no sistema de vendas, em situações onde clientes tentam efetuar compras através de smartphones: por ser muito pesado para este tipo de terminal e necessitar de aplicativos específicos, o sistema acaba ficando lento, e o cliente não finaliza a compra. Cerca de $34 \%$ dos consumidores que clicam em "comprar" não finalizam a compra. Para os clientes identificados pelo cadastro do sistema, são enviados e-mails "Finalize sua compra", na tentativa de reverter a perda, mas apenas $20 \%$ destes e-mails surtem resultado positivo.

Resultado da perda: há perda no processamento.

4) Perdas por produzir produtos defeituosos: do total de produtos entregues, aproximadamente $4 \%$ chegam à casa do consumidor final com algum tipo de avaria. A substituição do produto avariado é garantida, e gera custos de transporte e logística: produtos com avarias geram o dobro dos gastos com transporte. A responsabilidade financeira pela substituição do item é do operador logístico contratado, porém, este repasse de valores não vem acontecendo, e a empresa arca com todos os custos da entrega do novo item.

Resultado da perda: há perda por produção de produtos defeituosos.

5) Perdas por estoque: o sistema permite que seja feito um controle de itens procurados e não encontrados no site: toda vez que algum cliente em potencial digita e busca por algum produto no site e não há disponibilidade do item nos estoques, o sistema contabiliza a procura e classifica por categoria. Dessa maneira há dados concretos sobre itens mais procurados e perda de oportunidade de venda, uma vez que se houvesse estoque do produto, possivelmente seria efetuada uma venda.

Resultado da perda: há perda por estoques.

6) Perdas por movimentação: entregas canceladas por atraso e substituição de produtos entregues com avarias geram altos custos financeiros, além de tomarem tempo e mão de obra: o produto é retirado da casa do cliente, que deverá receber outro, em perfeito estado (em caso de avarias); e nos casos de cancelamento, muitas vezes o produto já está a caminho, e deve retornar 
para o centro de distribuição. Também ocorrem perdas pela movimentação dos produtos de uma empresa para outra durante o transporte até o endereço de entrega, visto que há subcontratação de operadores logísticos, e os produtos passam por mais de uma empresa até chegar ao destino.

Resultado da perda: há perda por movimentação

7) Perdas de tempo disponível (espera): cerca de $30 \%$ dos consumidores que tem algum problema de avaria e entrega fora do prazo cancelam a compra. Desta forma há custo alto com movimentação (baixa e ativação de estoque), mão de obra para enviar produtos, pagamento do frete (tanto para buscar o produto na casa do consumidor, quanto para enviar o produto originalmente solicitado).

Resultado da perda: há perda por espera

O Quadro 2 apresenta uma matriz das perdas identificadas em relação a cada departamento para ter a dimensão mais clara destes impactos.

Quadro 2: Relação entre os Setores x Perdas

\begin{tabular}{|c|c|c|c|c|c|c|c|}
\hline Setores/Desperdício & 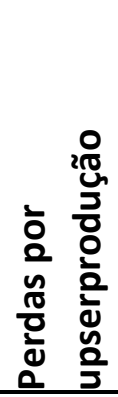 & 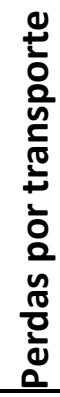 & 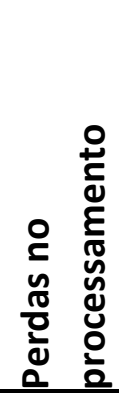 & 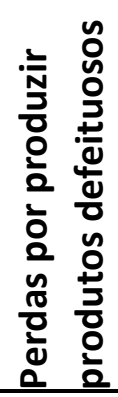 & 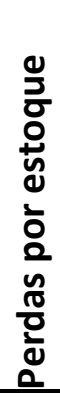 & 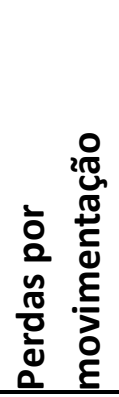 & 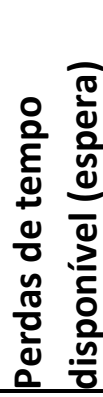 \\
\hline Departamento Comercial & $x$ & & & & $x$ & & \\
\hline Sistema de Gestão online & & & $x$ & & $x$ & $x$ & \\
\hline Operações Logísticas & & $x$ & & $x$ & & $x$ & $x$ \\
\hline
\end{tabular}

No departamento comercial, foram identificadas as perdas por superprodução e perdas por estoque. No departamento de Gestão online foram as perdas no processamento, perdas por estoque e perdas por movimentação. E por fim, no departamento logístico foram identificadas as perdas por transporte, perdas por produzir produtos defeituosos, perdas por movimentação e perdas de tempo disponível (espera).

\section{CONSIDERAÇÕES FINAIS}

É necessário entender que o sistema "enxuto" é muito mais que um método para eliminação de perdas do sistema produtivo, é uma nova maneira das pessoas trabalharem comprometidas com o alcance dos objetivos organizacionais.

Observa-se a flexibilidade dos conceitos pertinentes ao STP. Tais conceitos mostraram-se genéricos o suficiente e aplicáveis em um tipo de processo bastante distinto daqueles que 
motivaram a sua proposição original. Sua aplicação em outros setores, de tal forma, é altamente recomendada.

Nesse sentido, essa pesquisa soma-se aos esforços anteriores questionando e reconstruindo o conceito de Perda do Sistema Toyota de Produção, amplamente perseguido pelas organizações brasileiras. Foi realizada a primeira etapa necessária para diagnosticar as perdas existentes no processo, através da identificação dos desperdícios e dos setores envolvidos. A partir deste estudo inicial, busca-se para trabalhos futuros a aplicação prática para análise e melhorias no processo.

\section{REFERÊNCIAS}

Anzanello, M. J., Falcão, A. G, Fogliatto, F. S. \& Filomena, T. P. (2009). Análise de perdas e melhorias baseadas em conceitos de Produção Enxuta na indústria vinícola, Revista Gestão Industrial, 5(1), pp.141-154.

Antunes Júnior., J. A. V. (1998). Em Direção a uma Teoria Geral do Processo na Administração da Produção; uma discussão sobre a possibilidade de unificação da teoria das restrições e da teoria que sustenta a construção dos sistemas de produção com estoque zero. Tese de Doutorado, Universidade Federal do Rio Grande do Sul, Porto Alegre, RS, Brasil. 399p.

Antunes Júnior., J. A. V. (1995). A Lógica das Perdas nos Sistemas de Produção; uma análise crítica, Revista Brasileira de Administração Contemporânea, 1(7), pp.35-371.

Antunes Júnior., J., Alvarez, R., Klippel, M., Pellegrin, I. \& Bortolotto, P. (2008). Sistemas de Produção: Conceitos e Práticas para Projeto e Gestão da Produção Enxuta. Porto Alegre: Bookman. 326p.

Antunes Júnior., J. A. V. \& Klippel, M. (2002). Análise crítica do inter-relacionamento das perdas e dos subsistemas do sistema Toyota de produção. Anais do Encontro Nacional de Engenharia de Produção. Curitiba, PR, Brasil, 22.

Bornia, A. C. (2002). Análise gerencial de custos: aplicação em empresas modernas. Porto Alegre: Bookman.

Corrêa, H. L. \& Gianesi, I. G. N. (1993). Just in Time, MRP // e OPT: Um Enfoque Estratégico. São Paulo: Atlas.

E-Bit (2015). Comércio Eletrônico cresce 24\% em 2014 e maior acesso aos Smartphones ajuda a Alavancar Mobile Commerce. Recuperado de:http://www.ebitempresa.com.br/clip.asp?cod_noticia=3958\&pi=1. 
Gil, A. C. (2010). Como elaborar projetos de pesquisa. São Paulo: Atlas. 175p.

Ghinato, P. (1994). Elementos para a Compreensão de Princípios Fundamentais do Sistema Toyota de Produção: Autonomação e Zero Defeitos. Dissertação de Mestrado, Universidade Federal do Rio Grande do Sul, Porto Alegre, RS, Brasil.

Ghinato, P. (1995). Sistema Toyota de produção: mais do que simplesmente Just-inTime. Production, 5(2), 169-189. https://dx.doi.org/10.1590/S0103-65131995000200004

Falcão, A. S. G. (2001). Diagnóstico de perdas e aplicação de ferramentas para controle de qualidade e melhoria do processo de produção em uma etapa construtiva de edificações habitacionais. Dissertação de Mestrado, Universidade Federal do Rio Grande do Sul, Porto Alegre, RS, Brasil. 165p.

Jiang, Y., Shang, Y., Liu, Y., \& May, J. (2015). Redesigning promotion strategy for e-commerce competitiveness through pricing and recommendation. Journal of Production Economics, 167, pp. 257-270.

Jornal Data Folha. (2014). Retirado de: datafolha-comprova-walmart-brasil-tem-o-menor preo57.html.

Marconi, M. A. \& Lakatos, E. M. (2010). Metodologia Científica: Ciência e conhecimento científico; método científico; teoria, hipóteses e variáveis e metodologia jurídica. São Paulo: Atlas.

Marett, K., Pearson A. K., Pearson, R. A. \& Bergiel, E. (2015). Using mobile devices in a high risk context: The role of risk and trust in an exploratory study in Afghanistan. Technology in Society, 41, pp. $54-64$.

Menegon, D., Nazareno, R. R. \& Rentes, A. F. (2003). Relacionamento entre desperdícios e técnicas a serem adotadas em um Sistema de Produção Enxuta. Anais do Encontro Nacional de Engenharia de Produção. Ouro Petro, MG, Brasil, 23.

Mohammada, R. M., Thabtahb, F. \& Mccluskey, L . (2015). Tutorial and critical analysis of phishing websites methods. Computer Science Review, 17, pp.1-24.

Moreira, D. A. (2011). Administração da produção e operações. São Paulo: Cengage Learning.

Monden, Y. (2011). Toyota production system: an integrated approach to just-in-time. CRC Press. $566 p$.

Neto, M. V. J. (2006). Perdas de produtividade devido à produção de peças defeituosas: um estudo de caso no setor de montagem em uma indústria fabricante de máquinas têxteis. Revista Intersaberes, 1 (1), pp. $137-167$. 
Ohno, T. (1997). O Sistema Toyota de Produção - Além da Produção em Larga Escala. Porto Alegre: Bookman.

Reddy, N. A. \& Divekar, B. R. (2014). A Study Of Challenges Faced By E-Commerce Companies In India And Methods Employed To Overcome Them. Procedia Economics and Finance. 11, pp. 553 -560 .

Shingo, S. (1996a). Sistema Toyota De Produção: Do Ponto-De-Vista de Engenharia de Produção. Porto Alegre: Bookmann.

Shingo, S. (1996b). Sistema de Produção com Estoque-Zero: O Sistema Shingo para Melhorias Contínuas. Porto Alegre, Editora Bookman.

Slack, N., Chanbers, S. T. \& Johston, R. (2002). Administração da Produção. São Paulo: Atlas.

Spear, S. \& Bowen, H. K. (1999). Decoding the DNA of the Toyota Production System. Harvard Business Review, 77 (5), pp.96-108.

Walmart. (2014). Site Institucional. Retirado de: http://www.walmart.com.br/.

Womack, J. P. \& Jones, D. T. (1998). A Mentalidade Enxuta nas Empresas - Elimine Desperdício e Crie Riquezas. Rio de Janeiro: Campus. 